\title{
Bibliotecas para un tiempo de crisis: Edificio y personal
}

\author{
Juan José FUENTES ROMERO \\ Investigador \\ 123xxf@gmail.com
}

Recibido: Diciembre 2011

Aceptado: Junio 2012

Resumen: Partiendo de una definición de lo que para nosotros significa "crisis", y utilizando una metodología sistémica, se analiza brevemente la situación del libro, las editoriales y las bibliotecas. El núcleo de este artículo está formado por el estudio de esa crisis en cuanto a las bibliotecas en su conjunto, así como respecto al edificio e instalaciones y al personal.

Palabras clave: Bibliotecas-Crisis económica; Crisis en los libros; editoriales y librerías; Bibliotecas-Edificios e instalaciones; Bibliotecas-Personal.

\section{Libraries for a time of crisis. Building and staff}

\begin{abstract}
From a definition of "crisis", and using a systemic methodology, here appears questions as books, publishing and bookshops. The core of this article is about the library in itself considered, as well as building, equipment and staff. In the conclusions it is signed up how crisis is a threat, obviously, but as well it represents opportunities.
\end{abstract}

Keywords: Libraries; Economical Crisis; Crisis in books; publishing and bookshops; Library buildings; Staff library.

\section{INTRODUCCIÓN: ¿QUÉ ES REALMENTE UNA CRISIS?}

Parece, si queremos enterarnos realmente del significado de esta palabra, que lo más adecuado es recurrir a un diccionario, al DRAE (Diccionario de la Real Academia de la Lengua Española) en nuestro caso. De las diversas entradas (7 en total) que para esta palabra, crisis, presenta dicho Diccionario, las más adecuadas en nuestro caso son las correspondientes a los números 4, (Momento decisivo de un negocio grave y de consecuencias importantes), 6 (Escasez, carestía) y 7 (Situación dificultosa o complicada).

Aunque es indudable que la crisis actual tiene muchas vertientes y se presenta en diversos campos del vivir humano, parece evidente que de manera esencial es en el dominio de lo económico donde con más fuerza vemos sus connotaciones; otra cuestión, en un primer vistazo meramente introductorio, es la que se refiere al carácter internacional, global, de la tal crisis, ya que al parecer no hay ni un solo país que se esté librando de ella. Crisis equivale a una coyuntura de cambios en 
cualquier aspecto de una realidad organizada pero inestable, sujeta a evolución; especialmente, la crisis de una estructura. Los cambios críticos, aunque previsibles, tienen siempre algún grado de incertidumbre en cuanto a su reversibilidad o grado de profundidad, pues si no serían meras reacciones automáticas como las físico-químicas. Si los cambios son profundos, súbitos y violentos, y sobre todo si traen consecuencias trascendentales, van más allá de una crisis y se pueden denominar revolución.

La crisis financiera desde el 2007 al presente, o la Gran Recesión como ahora también se le denomina por parte de algunos, es una crisis provocada en su origen por una falta de liquidez en el sistema bancario de los Estados Unidos. Ha dado como consecuencia un colapso en las más grandes instituciones financieras, el control de bancos por los gobiernos nacionales y el descenso en las bolsas de valores a nivel mundial. En muchas áreas, el mercado inmobiliario también ha sufrido daños, ocasionándose numerosos desahucios, ejecuciones hipotecarias y un número cada vez mayor de viviendas vacías. Muchos economistas consideran que ésta es la peor crisis financiera desde la Gran Depresión de 1929 y es evidente que ha contribuido al fracaso de negocios de la mayor importancia, a una caída en la riqueza de los consumidores estimada en trillones de dólares USA, a los sustanciales endeudamientos en que han incurrido los gobiernos y a un descenso generalizado en la actividad económica. Los expertos han señalado una amplia variedad de causas, de distinta importancia, para explicar la presente crisis, de modo que se han propuesto soluciones que van desde las basadas exclusivamente en el control de los mercados a las puramente reguladoras.

\section{LA PERSPECTIVA SISTÉMICA}

Para analizar cuál sea la influencia de la crisis sobre las bibliotecas, y muy especialmente sobre las bibliotecas públicas, puede servirnos como método de actuación la perspectiva sistémica. Procede pues que, como punto de partida, dejemos claro a qué nos estamos refiriendo cuando hablamos de sistema. Podemos dar como buena la definición según la cual un sistema es un conjunto de partes o elementos organizados y relacionados que interactúan entre en sí para llegar a un mismo objetivo. Los sistemas reciben (input:entrada) datos, energía o materia del ambiente y tienen como resultado que proveen (output:salida) información, energía o materia. Los sistemas tienen límites o fronteras, que los diferencian del ambiente. Ese límite puede ser físico (el despacho de un ordenador) o conceptual. Si hay algún intercambio entre el sistema y el ambiente a través de ese límite, el sistema es abierto, de lo contrario estaríamos en presencia de un sistema seria cerrado. El ambiente es el medio externo que envuelve física o conceptualmente a un sistema. El ambiente puede ser para el sistema tanto una amenaza como algo positivo. Per se, un sistema puede ser conceptual o real. Un sistema conceptual o sistema ideal es un conjunto organizado de definiciones, nombres, símbolos y 
otros instrumentos de pensamiento o comunicación. Ejemplos de sistemas conceptuales son las matemáticas, la lógica formal o la notación musical. Un sistema real es una entidad material formada por partes organizadas (sus "componentes") que interactúan entre sí de manera que las propiedades del conjunto no pueden deducirse por completo de las propiedades de las partes. Tales propiedades se denominan propiedades emergentes. Los sistemas reales intercambian con su entorno energía, información y, en la mayor parte de los casos, también materia. Una célula, un ser vivo, la Biosfera o la Tierra entera son ejemplos de sistemas naturales. El concepto se aplica también a sistemas humanos o sociales, como una sociedad entera, la administración de un estado, un ejército o una empresa. $\mathrm{O}$ a una lengua, que es un sistema conceptual complejo en cuya aparición y evolución participan la biología y la cultura.

Resulta evidente que, a partir de lo hasta aquí expuesto, una biblioteca es un sistema humano o social en el que cabe distinguir un entorno externo y otro interno. Quiere esto decir, como es bien sabido, que tanto desde el entorno externo (todo lo que ocurre desde fuera de la biblioteca) como desde el entorno interno (lo que sucede dentro de la biblioteca misma) se produce un juego de influencias que en todo momento están afectando a dicha biblioteca. Vamos a analizar, siquiera brevemente, cuáles son o pueden ser dichas influencias y, siempre desde la perspectiva de la crisis, de qué manera afectan a esta institución, la biblioteca, objeto de este estudio.

En primer lugar procede hablar de la crisis en sí misma considerada como elemento externo a la biblioteca y que está actuando totalmente sobre ésta. Hasta los inicios de la actual crisis, en al menos muchos de los Estados occidentales hemos vivido en lo que se ha dado en llamar "sociedad del bienestar", caracterizada por la consecución, para la mayoría de los ciudadanos, de un alto nivel de vida, con elevado consumismo, cobertura por parte del Estado de las diversas necesidades sociales tales como el acceso a la educación, la sanidad, las comunicaciones y transportes, la cultura, etc. Resulta evidente que, incluso en los Estados más avanzados en la protección social (los países nórdicos, por ejemplo) dicho "estado del bienestar" tiene sus días contados, de modo que los servicios sociales citados resultan cada día más recortados, eso si no están desapareciendo totalmente. Se ha citado la oscilación de precios del petróleo como principal causa financiera de esta crisis y, como consecuencia en el ámbito público, unos rigurosos programas de estabilidad presupuestaria. En el ámbito financiero no hay grandes discrepancias en este tiempo en los países más avanzados, por lo que se puede hablar de un pensamiento hegemónico que en sus soluciones mezcla las tradicionales medidas de recorte en el gasto social, que tratan de paliar los crecientes desequilibrios sociales, con otras de restricción general del gasto y de limitación del endeudamiento [Arenilla Sez].

Desde el enfoque de nuestras bibliotecas, y esto sucede en cualquiera de los países de nuestro más inmediato entorno, la cuestión es que se siguen manteniendo las 
bibliotecas públicas (¿Qué político, por ahora, se atrevería a suprimirlas?), cierto es, pero no es menos cierto que la restricción presupuestaria en estos centros está llegando la mayoría de las veces a niveles reales de penuria. Escapa a los límites de este trabajo el estudio referente a cómo, y hasta qué nivel, los presupuestos públicos han supuesto desde hace años recortes en todas las partidas referentes a cultura y, dentro de éstas, las tocantes a las bibliotecas; esto sería analizable en las diversas administraciones, desde la municipal a la estatal, pasando por las autonómicas; dicho estudio sería, sin lugar a dudas, enormemente esclarecedor.

Las carencias presupuestarias conllevan paradójicamente unos niveles de exigencia cada vez mayores, por parte de los usuarios, en cuanto a la calidad y cantidad de los servicios que la biblioteca pueda ofrecerles. Como consecuencia del antes citado Estado del Bienestar, al menos en los países más desarrollados, los ciudadanos se han acostumbrado a unos niveles mínimos de calidad en los servicios públicos. La exigencia de dichos niveles aparece como difícilmente compatible con los recortes presupuestarios, a veces elevadísimos, que están sufriendo todos los organismos que componen la Administración Pública, y las bibliotecas, obviamente, no sólo no suponen ninguna excepción al caso sino que cada vez con más frecuencia figuran entre los más afectados.

\section{LIBROS, EDITORIALES Y LIBRERÍAS}

Desde fuera de las bibliotecas, y analizando siquiera brevemente el estado actual del circuito del libro desde el autor hasta su lector, resulta en grado sumo esclarecedor contemplar, dentro de este enfoque global, la situación de las editoriales y de las librerías. No obstante lo dicho tal vez debiéramos considerar, al menos como punto de partida, que en el origen de todo lo referente a las bibliotecas está el libro y, por tanto, tendríamos que analizar la manera en que la crisis está afectando a los libros. En una entrevista al conocido editor Jorge Herralde (25/09/2008), de Anagramaeste afirmaba que "La crisis actual afectará al sector como en todo, pero la hipótesis optimista es que el libro tiene un valor de 'refugio', los libros no son caros pese a la 'eterna cantinela', ya que hay una oferta muy buena en libros de bolsillos, con títulos fantásticos y muy bien editados. Además, el auténtico lector necesita leer, y es más 'barato' comprarse un libro que ir a otras cosas placenteras como un concierto de rock o un partido de fútbol. En tiempos de crisis, la hipótesis optimista es que los libros no sufren tanto" [Herralde].

\subsection{LAS EDITORIALES}

En cuanto a las editoriales, es fácil señalar que la mayor o menor incidencia de la crisis en este sector empresarial viene dada por el tamaño de dichas empresas; en cuanto a las más grandes de entre ellas el fenómeno más destacable 
posiblemente sea el de la concentración en cada vez más extensos holdings, de modo que ésta parece ser la tendencia predominante. No quiere decir que sea la panacea frente a las situaciones de extremo peligro que día a día se plantean, pero la unión conlleva un mayor control sobre cada vez más amplios mercados $\mathrm{y}$, sobre todo, el poder disponer de mejores canales de distribución. En un artículo publicado en el diario español "El País" (3 de Julio del 2009) desde la Federación de Gremios de Editores se señala que "La situación es grave y nos obliga a replantearnos tácticas y estrategias"[Federacion, 2011].

Así mismo, en el Discurso de Inauguración de la Feria del Gremio de Editores de España, LIBER 2010, su presidente afirmaba: "Se ha llegado a extender la idea, ayudada en gran parte por la Prensa, de que la crisis no estaba afectando al Sector del Libro. Tal cosa no es cierta...". Atendiendo a las magnitudes del año 2009, el Sector, en su mercado interior, descendió un $2,4 \%$ en ventas, lo que, no siendo un buen resultado, queda lejos de los descensos de dos dígitos habidos en otros sectores. Las ventas al exterior descendieron, debido principalmente a la caída de los coleccionables, línea cuyo modelo de negocio da síntomas de estar en fase de replanteamiento. Sin embargo, en el resto de productos se han sostenido airosamente, si bien es verdad que con grandes inversiones y esfuerzos, esfuerzos que no se deben abandonar. La existencia, evidente por otra parte, de una crisis en el sector editorial viene demostrada, sensu contrario, por la preparación por parte del citado Gremio de un Plan Estratégico para el Sector del Libro cuyas líneas más generales son:

- La necesidad de una modificación y actualización de la Ley de Propiedad Intelectual, en armonía con la Unión Europea

- Medidas fiscales de apoyo a la industria y al comercio del libro

- Necesario fortalecimiento de la política de incremento de Fondos Bibliográficos a las Bibliotecas Públicas, Escolares y Universitarias.

- Un marco estable y pedagógicamente sólido y contrastado, acorde con las conclusiones de los estudios llevados a cabo por la OCDE para el libro de texto y otros materiales educativos.

- La transformación necesaria del modelo de negocio y del comercio del libro, dentro del cual se valora especialmente el apoyo a la librería independiente para que pueda acometer esa transformación. [LIBER 2010]

\subsection{LAS LIBRERÍAS}

$\mathrm{Si}$, desde el mundo editorial lanzamos a continuación un vistazo a lo que sucede en las librerías, no se puede decir que la crisis les esté pasando de largo. Creemos que son perfectamente asumibles las afirmaciones que se exponen en el blog Paradigma Libro, en el artículo "En el corazón de la crisis: El pinchazo de la 
burbuja editorial". Hay que zambullirse de lleno en el día a día de editores y librerías para cobrar conciencia de hasta qué punto la burbuja editorial de estos últimos años, al igual que la burbuja inmobiliaria, también ha pinchado. Enumeramos así varios de los efectos de la crisis en el sector del libro: - Quiénes se ha resentido antes: Las cadenas y grandes superficies y las librerías con mucha venta institucional. Estas han sido las primeras en sufrir el impacto, esencialmente porque dependen del "tráfico" a tienda y de la compra por impulso. Las librerías con ventas institucionales, es decir, a bibliotecas, ministerios, facultades, bibliotecas públicas, etc. La morosidad administrativa a la hora de liquidar las compras les tiene en una situación desesperada. - Quien comienza a resentirse: La librería tradicional. A pesar de tener una clientela muy estable notan que esos clientes espacian más su visita a la tienda y su compra media es inferior, en número de títulos y en volumen. - Efectos generales sobre el sector:

- Aumento de la profundidad de las devoluciones, esencialmente para liberar activos y reducir la financiación a terceros por parte de las librerías.

- Como consecuencia del aumento de las devoluciones se observa una disminución de la visibilidad de muchos títulos.

- Menor profundidad del fondo de catálogo en las tiendas.

- Implantaciones mucho más bajas y cautelosas.

- Compras más ajustadas.

- Compra media por cliente inferior en volumen y en el número de ejemplares.

- Menor visibilidad de títulos que no aseguren al menos una rotación potencial amplia.

- Liquidaciones menguantes de los distribuidores a los editores.

- Fuerte presión de las grandes cadenas sobre los editores para aumentar en algún punto el margen.

- Como consecuencia de las razones expuestas, en ese mismo blog se plantean las cuestiones siguientes:

- ¿Qué capacidad de aguante tiene el sector del libro?

- ¿Se está trabajando en un plan anticrisis?

- ¿El precio fijo no supone un freno a la hora de estimular la demanda? ¿Hasta qué punto es acertado y oportuno que el discurso de los editores lanzado desde la Federación de Gremios de Editores de España a la sociedad, como respuesta a la crisis, sea la campaña del "bolsilibro"? ¿Responde a las necesidades reales del sector? ¿A qué intereses económicos, y de quién, responde si no?" [Paradigma].

Desde las mismas páginas citadas de "Paradigma libro", con fecha de 14 de Julio de 2010, y bajo el título de "Muerte súbita de las librerías" se afirma lo que sigue: "Las cifras de COMERCIO INTERIOR 2009, independientemente de que se tengan 
reparos a la hora de considerarlas totalmente fiables, son malas, muy malas. Baja la venta total, la tirada media, el número de ejemplares editados y vendidos, y lo único que sube es el número de títulos editados, que aumenta un 4,43\%. La crisis de sobreproducción es evidente. ¿Qué visibilidad tienen esos títulos?.

Aunque este análisis sobre las librerías en la crisis y su relación con el mundo de las bibliotecas no pretende ser exhaustivo, conviene no olvidar el papel que cada vez con más fuerza vienen jugando las librerías virtuales. Citaremos, como más conocido, lo referente a la librería Submarino, sin olvidar a la posiblemente mayor entre todas, Amazon, como es bien sabido.

Acabamos este rápido repaso a las consecuencias de la crisis sobre las librerías citando, también a partir del blog "Paradigma libro" la información que proporciona la Federación de Gremios de Editores de España en el informe de Comercio Interior. [Federación de Gremios de Editores de España. Comercio Interior] Desde este enfoque de las librerías, se señala en dicho informe que, en general, es el libro de bolsillo el material que menos está sufriendo la real y cierta crisis económica, de modo que sus ventas no sólo no decaen sino que debido a su menor precio ( $10 €$ de media, frente a los 20 o 30 del libro en pasta dura) incluso están aumentando. Conviene señalar, no obstante, y es nuestro este comentario, que por su poca consistencia, fragilidad y consiguiente escasa duración es precisamente éste, el libro de bolsillo, el tipo de libro que menos se acomoda a los requisitos exigibles por parte de las bibliotecas en las que, por el continuo uso de su colección de materiales, interesan más los ejemplares encuadernados.

Recapacitando en lo hasta aquí comentado vemos cómo la crisis está afectando, y seriamente, tanto al libro como a las editoriales y a las librerías; esto hace que, en consecuencia, las bibliotecas también resulten "tocadas" por estos condicionantes negativos pues de sobras es por todos conocidos el hecho más que evidente de que, por ahora, tanto las editoriales como las librerías son los grandes proveedores de materiales de las bibliotecas.

\section{LAS BIBLIOTECAS}

Siguiendo con el enfoque sistémico desde el cual analizamos la situación y las posibles actuaciones de la biblioteca en estos tiempos de crisis nos centramos ahora en las bibliotecas en sí mismas consideradas y, a continuación, en dos de sus más importantes componentes: el edificio y el personal. Aclaramos que la amplitud de los temas a tratar nos ha llevado a no incluir en este artículo las cuestiones referentes a las colecciones, los servicios y los presupuestos, que serán materia de otro artículo.

Resulta un tópico referirnos al papel de la UNESCO al establecer los valores que en la actualidad conlleva, o debe conllevar, la biblioteca pública, y no por tópicos hay que dejar de mentar dichos valores. Permítasenos la cita, larga pero imprescindible, de los párrafos de introducción del Manifiesto sobre las 
bibliotecas: "La libertad, la prosperidad y el desarrollo de la sociedad y de la persona son valores humanos fundamentales que sólo podrán alcanzarse si ciudadanos bien informados pueden ejercer sus derechos democráticos $\mathrm{y}$ desempeñar un papel activo dentro de la sociedad. La participación constructiva y la consolidación de la democracia dependen de una buena educación y de un acceso libre e ilimitado al conocimiento, el pensamiento, la cultura y la información. La biblioteca pública, paso obligado del conocimiento, constituye un requisito básico de la educación permanente, las decisiones autónomas y el progreso cultural de la persona y los grupos sociales. Este Manifiesto proclama la fe de la UNESCO en la biblioteca pública como fuerza viva de educación, cultura e información y como agente esencial de fomento de la paz y los valores espirituales en la mente del ser humano. Así pues, la UNESCO alienta a las autoridades nacionales y locales a que apoyen las bibliotecas públicas y participen activamente en su desarrollo" [UNESCO. Manifiesto]. Así mismo, y en estos tiempos más que nunca conviene recordar, por la crudeza de las circunstancias, que "La biblioteca pública presta sus servicios sobre la base de igualdad de acceso de todas las personas, independientemente de su edad, raza, sexo, religión, nacionalidad, idioma o condición social. Debe contar además con servicios específicos para quienes por una u otra razón no puedan valerse de los servicios y materiales ordinarios, por ejemplo, minorías lingüísticas, deficientes físicos y mentales, enfermos o reclusos". [UNESCO. Manifiesto. Ibidem].

Entre los años 2001 y 2003 se llevó a cabo el Proyecto Pullman, financiado por la Dirección General de la Sociedad de la Información (dentro del $5^{\circ}$ programa marco, IST "Information Society Technologies") de la Comisión Europea. Es la continuación de PubliCA, la acción concertada para bibliotecas públicas. Este proyecto parte de la idea de que "Las bibliotecas públicas europeas y las organizaciones culturales desempeñan un importante papel en el desarrollo de la llamada Europa electrónica y de la Sociedad de la Información. La Red PULLMAN quiere promover el intercambio de políticas y experiencias en Tecnologías de la Información y Comunicación entre las bibliotecas, archivos y museos de Europa; en definitiva entre las organizaciones culturales que trabajan en el ámbito local y regional".

Al analizar "El entorno de las políticas sociales y económicas", y dentro del epígrafe "Marginación y exclusión social" el Proyecto señala como "entre los factores de riesgo que aumentan la amenaza de la pobreza y de la marginación en Europa se encuentran: el desempleo de larga duración, el percibir bajos ingresos, los contratos basura de trabajo, el fracaso escolar y la falta de formación, el crecer en el seno de familias cercanas a la marginación social, la discapacidad, el padecer enfermedades, la drogadicción y alcoholismo, el vivir en zonas marginales o con desventajas, la falta de vivienda, y la discriminación racial".

Como solución a estos graves problemas se señala que "Las bibliotecas públicas pueden seguir ayudando a luchar contra la marginación social: 
- Haciendo que la integración se convierta en una política prioritaria dentro de todos los servicios de información y de biblioteca

- Adaptando algunos servicios específicos a las necesidades de grupos y comunidades minoritarias en cada zona

- Consultando e integrando a los grupos socialmente excluidos

- Creando bibliotecas donde exista una demanda

- Siendo más flexibles con los horarios de apertura

- Ajustándose a los intereses y necesidades de la comunidad a la que sirve

- Ofreciendo información y puntos de acceso a las tecnologías de la información y comunicación a precios asequibles o gratuitos;

- Actuando conjuntamente con otros servicios ofrecidos por la administración local y

- Estableciendo contactos con ONGs y centros de enseñanza para desarrollar y ofrecer servicios. [Pautas Pullman]

A los efectos de este trabajo, también resulta de interés señalar la actuación de la Subdirección General de Bibliotecas de la Generalitat de Cataluña que llevó a cabo, en 2009, una encuesta sobre lo que diversos agentes, tanto externos a las bibliotecas como profesionales de ellas, pensaban que podría o tendría que ser la biblioteca en este siglo XXI en el que ya nos encontramos. Dicha encuesta lleva por nombre "Imagina la biblioteca del siglo XXI. Extracción de datos de las encuestas". La cuestión 1 que se plantea responde a la pregunta de "Para qué tendrían que servir las bibliotecas públicas" y reproducimos íntegramente las 15 respuestas:

1. Asesoramiento de los profesionales, ayuda, asistencia

2. Civismo, fomento de la democracia, formación cívica

3. Cultura, centro cultural, espacio cultural, intercambio cultural, acceso a la cultura

4. Derecho social, garantía, acceso universal

5. Espacio de integración, de identidad colectiva, cohesionador social, fomento del espíritu comunitario

6. Estudio, investigación, erudición

7. Fomento lector, fomento de la promoción de la lectura

8. Formación continua, educación, ayuda al estudio formal y no formal, enseñanza a lo largo de toda la vida, autoformación, formación de usuarios

9. Información: acceso a, búsqueda, selección, distribución, redistribución, difusión, comunicación

10. Lectura

11. Ocio, entretenimiento

12. Preservación, memoria 


\section{Préstamo}

14. Recursos, fuentes, documentación, materiales, medios, documentos de calidad, contenidos

15. TIC, innovación.’[Catalunya. Generalitat]

La segunda cuestión que plantea esta encuesta se refiere a los puntos fuertes que, según los encuestados, presenta la biblioteca pública. A los efectos de nuestro trabajo nos interesan especialmente las dos primeras respuestas, las que se refieren a las actividades y a la comunidad. Respecto a las actividades se afirma:"Actividades orientadas a los diferentes segmentos de usuarios, la biblioteca como centro cultural, equipamiento cultural, polifuncional, nuevos servicios de espacio cultural". En cuanto a la comunidad:"Creación de comunidad, integración de los recién llegados, proximidad de la biblioteca con la comunidad, lugar/punto de encuentro, capacidad de colaboración, respuesta a las necesidades locales" [Catalunya. Generalitat: Ibidem].

Esta misma idea de biblioteca, entendida ésta como institución que de suyo es esencial para conseguir la inclusión y la cohesión social, se manifiesta en la "Declaración de Murcia sobre la acción social y educativa de las bibliotecas públicas en tiempo de crisis" (Murcia, Biblioteca Regional, 19 de febrero de 2010) cuando, en el punto primero de dicha declaración afirma: "1. Las bibliotecas realizan una función social y educativa, de apoyo a las personas y comunidades en todo momento. Pero, particularmente, pueden ser un recurso fundamental de inclusión y promoción social cuando la crisis económica incrementa el número de personas en paro, precariedad laboral, vulnerabilidad o exclusión social" [Castillo, Gómez y Quiles].

De especial interés, así mismo, nos resulta el punto 7 de dicha Declaración de Murcia: "Hay que transmitir y hacer que la sociedad conozca la función de la biblioteca como institución de formación permanente, inclusión social y puerta de acceso a la sociedad de la información para todos" [Castillo, Gómez y Quiles].

En estos planteamientos resulta meridianamente claro el papel de la biblioteca pública como centro de integración y cohesión social; no es que este papel no estuviese en la médula de lo que hasta ahora han sido las bibliotecas públicas, pero es a todas luces evidente que en estos tiempos de crisis resultan ser, las bibliotecas, una de las instituciones más y mejor preparadas para hacer frente a los retos que plantean los tiempos actuales.

$\mathrm{Si}$ de siempre han sido necesarias las bibliotecas, todas ellas y muy especialmente las bibliotecas públicas, mucho más lo son en estos tiempos de crisis, cuando una buena parte de la población encuentra que cada vez son más los recortes en los servicios públicos. Cualquier buen profesional sabe de sobras que el papel que las bibliotecas han venido ejerciendo tradicionalmente ha cambiado, y sigue y seguirá cambiando. La llegada de las tecnologías de la información y de la comunicación está en la base de dichos cambios, pero no son éstos obviamente los únicos. Globalmente considerado, el nuevo escenario que plantea la sociedad de la 
información y del conocimiento (SIC) es otro de los cambios que posiblemente más estén afectando a las bibliotecas. La acción conjunta de las Tecnologías de la Información y de la Comunicación, y de la SIC, hace que el libro como objeto material tenga una existencia como mínimo problemática en esta nueva arena. No se trata de que el libro "de papel" vaya a desaparecer (o no: el tiempo lo dirá), el hecho evidente es que los materiales, sean cualesquiera que sean los soportes, son cada vez más caros mientras que, como decíamos antes, los presupuestos se estancan. Al mismo tiempo, resulta también más que evidente que el nuevo rol que le toca jugar a la biblioteca no tiene en parte nada que ver con lo que ha sido su actuación tradicional: no es ya ese lugar respetable y respetado considerado algo así como la "catedral del saber". Ese saber no tiene ya un lugar físico desde el momento en que Internet permite acceder (al menos teóricamente) a una infinidad de páginas web desde las cuales informarnos de todo lo que queramos. Esto podría parecer una amenaza... pero también para las bibliotecas representa una oportunidad, ya que el nuevo tipo de usuarios ve a la biblioteca como un lugar de encuentros donde las tecnologías de la información y comunicación pueden estar accesibles de modo gratuito para todo el que lo solicite.

La crisis, quien lo diría, está al parecer influyendo -positivamente- en el crecimiento del número de personas que acuden a las bibliotecas. Esclarecedor resulta al respecto el artículo de Anna Grau, corresponsal en Nueva York del diario $\mathrm{ABC}$; su lectura no tiene desperdicio. [Grau]. Son las bibliotecas, siguiendo a la citada Anna Grau y como bien saben los buenos profesionales, lugares donde se suele estar cómodamente abrigados, en los cuales se puede acceder a la información de la prensa, ver cine, oír música, consultar Internet...y todo ello gratuitamente. Cierto es que nos estamos refiriendo a buenas bibliotecas, donde haya "de todo" y no a lo que con tanta frecuencia vemos y que es tan conocido que ni siquiera es preciso referirnos a ello.

Paradójicamente, este aumento en el número de usuarios viene acompañado, consecuencia directa de la crisis, de un descenso radical en el número de bibliotecas que se construyen.

En este sentido puede resultar pedagógicamente clarificador lo que informa el diario El País (17/04/2010): "Menos bibliotecas por culpa de la crisis: De los 30 equipamientos proyectados para 2009 sólo se construyeron 15". La noticia se refiere a Cataluña, con lo que mejor será que no indaguemos demasiado en lo que sucede en comunidades autónomas tales como Andalucía, Extremadura, Canarias [Montañés].

Como otra, una más, de las consecuencias que está representando la crisis para las bibliotecas, se ha señalado el hecho de que dentro de los nuevos roles que han de jugar, estos centros podrían actuar como lugares de búsqueda de empleo o como base de programas de asistencia social, fundamentalmente partiendo de los programas de alfabetización y de aprendizaje de técnicas de información. 
Como ejemplo de lo que estamos diciendo puede valernos la página de la Biblioteca Pública de Joliet, en el Estado de Illinois (Estados Unidos de América) que, indudablemente señala el camino a seguir por las bibliotecas públicas en tiempos de crisis. Es un tanto larga la cita que reproducimos pero, a nuestro entender, no tiene desperdicio: "Centro de Información de Crisis de la Biblioteca de Joliet: En momentos en que la comunidad está en crisis, las bibliotecas públicas juegan un papel crítico en la educación de la comunidad y en la difusión de información. Trabajando con otros servicios de emergencia, las bibliotecas proveen áreas de reunión, clases en seguridad para la familia, planes para continuar un negocio y así mismo proporcionan programas de información para casos de emergencia, lo mismo que presentaciones dirigidas a las organizaciones de la comunidad. En momentos en que la comunidad está en crisis, la gente responde emocionalmente y con sentido de urgencia para empezar a recobrar esfuerzos. Diversas Agencias de la comunidad se están uniendo y han creado un centro de información para todos en caso de crisis. La Biblioteca Publica de Joliet se ha asociado con el Departamento de Bomberos, con la Policía y el Departamento de Administración de Emergencias de la Ciudad y con otras agencias sociales, médicas y de negocios en un esfuerzo para establecer una red de información de crisis en Joliet.

Esta asociación es llamada Joliet Library Information Crisis Center (JLICC) y recibió una donación como punto de apoyo para publicitar sus actividades, animar a las bibliotecas públicas de Illinois y también para trabajar con otras agencias de la comunidad para hacer frente a situaciones de crisis o desastres, como en el caso de un tornado. Su prioridad es demostrar que esto supone un beneficio para la comunidad, de modo que se conozca la existencia de información accesible en un local en caso de crisis". [Joliet].

Como comentario por parte nuestra sólo vamos a llamar la atención sobre la perspectiva de colaboración con otros entes sociales que manifiesta esta biblioteca, con los bomberos, la policía, oficinas de la administración... Quizás por estas tierras aún estamos un poco lejos de ver las bibliotecas desde este enfoque. Cierto es que sobre el tema de la cooperación se teoriza todo lo que se quiera, y más. Otra cosa es la práctica.

Hasta aquí hemos analizado los agentes externos que actúan sobre la biblioteca y luego hemos presentado, siquiera someramente, el rol de la biblioteca en sí mismo considerada, siempre desde el enfoque de la situación de crisis en que vivimos. A continuación vamos, como ya decíamos anteriormente, a analizar algunos de los componentes de las bibliotecas, y más específicamente de las bibliotecas públicas, en dicho escenario de crisis. Nos referimos al edificio e instalaciones y al personal 


\section{EDIFICIO E INSTALACIONES. CRISIS Y SOSTENIBILIDAD}

No parece que haya que dedicar demasiados esfuerzos para demostrar que, en la medida en que la crisis afecta a las bibliotecas, afecta a todos y cada uno de sus componentes, entre ellos incluido, obviamente, todo lo referente al edificio y al equipamiento. Christine Mackenzie, en su artículo "Emerging themes for public libraries looking forward" señala en primer lugar que en la construcción de nuevas bibliotecas se va imponiendo la tendencia general a trabajar con la ratio de $1 / 3$ del espacio para las colecciones y $2 / 3$ de dicho espacio para los usuarios. Este giro en cuanto a la organización del espacio de las bibliotecas, de 180 grados podríamos decir sin exagerar, viene dado por el nuevo papel que desarrollan estos centros cuando, en momentos como los actuales, el acceso a la información es independiente del soporte y formato en que ésta se presenta. Es decir, cada vez más usuarios NO van a la biblioteca a consultar libros, sino a conectarse a Internet, oír música, ver la prensa, etc. En torno a ésta cuestión Mackenzie pone como ejemplo los casos de las bibliotecas OBA en Amsterdam [Openbare] y DOK [Dok] en Delft, en Holanda, las dos bibliotecas constituidas por espacios "dinámicos y fluidos, que crean un sentido de ser lugares para el aprendizaje y que responden a las necesidades contemporáneas y son lo suficientemente flexibles como para llegar a ser lo que la gente quiera que sean". [Mackenzie].

Otro caso citado es el de la Biblioteca 10 en Helsinki, en la que el mobiliario "es multifuncional y puede ser cambiado de lugar fácilmente para así poder crear espacios de trabajo individuales o, si es necesario, configurar otros ambientes a los que los usuarios pueden acceder o reunirse" [ elsinki].

En segundo lugar, Christine Mackenzie señala cómo ahora "los usuarios requieren santuarios dentro de la biblioteca, de modo que si antes existían espacios silenciosos y tranquilos para el trabajo individual, con áreas más pequeñas disponibles para actividades más ruidosas, ahora sucede lo contrario. Una de las quejas más frecuentes es que las bibliotecas se han transformado en lugares demasiado ruidosos, por lo que se requiere la creación de espacios silenciosos y tranquilos, incluso sin ninguna tecnología. Así, en la citada OBA hay tranquilos espacios para la lectura que realmente no están señalizados como tales, pero que son respetados por los usuarios que intuitivamente comprenden que éste es también uno de los roles de la biblioteca". También cita Mackenzie el caso de la nueva biblioteca de Oslo; al construir este nuevo centro se partió del concepto de ágora, de lugar de encuentro, de modo que el concurso para elegir el proyecto de construcción se basó en el concepto de edificio, y no en el diseño del interior. El edificio fue el más moderno y progresista de Europa en 1933 pero había llegado a ser algo "congelado hasta la muerte" [Oslo]. La nueva biblioteca integra lo físico y lo virtual, de modo que aunque continua con el préstamo de libros, resulta evidente que cada vez menos usuarios visitan la biblioteca para llevarse físicamente 
materiales. La biblioteca se ha transformado en un lugar al que va la gente y son muy diferentes las formas en que éstas se reúnen [Mackenzie, op. Cit.].

En épocas de crisis como ésta, y tal vez ya para siempre (como resultado, afortunadamente, de un cambio de valores respecto al trato que el ser humano ha de dar a su entorno y a la naturaleza en general), al hablar del edificio de la biblioteca hemos de tratar, inexcusablemente, la cuestión de la sostenibilidad. Puede servirnos de punto de partida al tratar este tema el planteamiento de IFLA en el Congreso Mundial de Gotemburgo, Suecia, en Agosto de 2010: "El interés por la problemática medioambiental es cada vez más central en la sociedad. Ahora bien, las bibliotecas de hoy hacen frente a las crisis energéticas, a los incrementos de precios de las materias primas, a las reducciones en las subvenciones públicas, $\mathrm{y}$ al aumento del consumo de recursos. Aunque surgen nuevas bibliotecas respetuosas del medio ambiente, la mayoría de las estructuras existentes siguen siendo lugares de consumo importante y de derroche de recursos. La cuestión consiste entonces en encontrar cómo desarrollar o convertir las bibliotecas en un modelo más sostenible, o al menos contribuyentes al modelo general del desarrollo sostenible" [IFLA 2010. Sostenibilidad].

Cuando IFLA hace la llamada para la presentación de comunicaciones al citado Congreso de Suecia, establece lo que podríamos denominar como la "hoja de ruta" para todo un programa referido a la sostenibilidad del edificio de la biblioteca y señala la articulación de este tema de la sostenibilidad respecto a una serie de puntos tales como los siguientes:

- Edificios: Renovar o adaptar las construcciones: ¿qué medios existen o se pueden desarrollar para reducir el impacto medioambiental sin construir nuevos edificios? Pensar o reconsiderar los sistemas eléctricos y de aire acondicionado, favoreciendo el alumbrado natural y aprovechando las condiciones climáticas locales.

- Personal: Respetar la salud y el bienestar de los usuarios y empleados: un punto central de la transformación duradera de la biblioteca. Evaluar los riesgos, sanitarios $\mathrm{u}$ otros, vinculados a los campos electromagnéticos al Wifi, el RFID, las nanotecnologías, etc. ¿Cómo asociar los usuarios a los programas de desarrollo sostenible?

- Usos: ¿Cómo hacer la utilización de las bibliotecas más respetuosa para con el medio ambiente? Las soluciones incluyen por ejemplo (lista no exhaustiva): la cooperación con las ONG medioambientales, el acceso fácil para los transportes suaves (bicicletas, patines...), la oferta de contenedores para reciclaje (metal, botellas, baterías...) o la promoción de bolsas no contaminantes (papel o algodón).

- Gestión y Dirección: ¿Qué directivas o lineamientos adoptar para las buenas prácticas en bibliotecas? ¿Cuáles son las herramientas ya existentes para ayudar a los empleados a trabajar de manera sostenible? ¿Qué herramientas y 
procedimientos ecorresponsables pueden desarrollar las bibliotecas para inscribirse mejor en el desarrollo sostenible en cuanto a funcionamiento interno? [IFLA 2010. Sostenibilidad].

\section{EL PERSONAL DE LAS BIBLIOTECAS}

Considerado el edificio como contenedor de lo que físicamente significa la biblioteca, y viendo cómo resulta dicho contenedor, e incluso la idea que de él se tiene, afectado por la crisis, otro tanto sucede respecto al personal. Realmente el binomio edificio - personal aparece como intrínsecamente unido, de modo que el uno (edificio) es el campo de actuación del otro (personal) mientras que es este quien con su labor da sentido y razón de ser a dicho edificio. Hablar de crisis como algo que, unido al edificio, afecta al mismo tiempo no es sino señalar una evidencia.

En la medida en que cambian las tecnologías, así cambian las habilidades que se requieren a los bibliotecarios. Considerado desde este enfoque, el desafío para la profesión bibliotecaria está en saber cuáles son las habilidades realmente necesarias en la era de la tecnología. Aparece un triángulo de elementos, edificio, personal y tecnologías que, desde la globalidad de la biblioteca pública, muestran claramente una triplicidad en la que cualquier cambio en uno de ellos va a afectar a los otros dos.

Una vez que hemos señalado algunas de las notas referentes al edificio en esta situación de crisis, procede, por tanto, estudiar cuáles son las habilidades, conocimientos y atributos necesarios para los profesionales de las bibliotecas en estos tiempos de crisis y cambio por la irrupción de las nuevas tecnologías. En consecuencia, es de vital importancia conocer las características que ha de cumplir el bibliotecario cuando aparece un nuevo escenario de actuación, el enmarcado en la web 2.0. Como es bien sabido, el concepto de biblioteca 2.0 hace referencia a la aplicación de la tecnología web 2.0 en el diseño y entrega de servicios bibliotecarios. Esto ha supuesto cambios realmente esenciales en las bibliotecas actuales, de modo que si hasta ahora las bibliotecas se han dedicado a contener libros e información, ahora, con la biblioteca 2.0 facilitan a sus usuarios participar, interactuar y crear; además, proporcionan los medios para que esto llegue a ser posible.

La aparición de esta biblioteca 2.0 ha generado un amplio debate dentro de la profesión bibliotecaria respecto a lo que realmente significa para la biblioteca tradicional; no obstante, existe un acuerdo general acerca de que lo realmente importante se refiere a las cualidades que la nueva situación exige a los profesionales, de modo que según estas opiniones los dichos bibliotecarios han de prepararse para actuar como bibliotecarios 2.0. Es necesario, aunque posiblemente superfluo a esta altura, señalar cómo la mayoría de estos pronunciamientos se producen, y sin cesar, mediante la participación de los bibliotecarios en los blogs ad hoc. En este sentido, se ha llegado a afirmar que el bibliotecario es el guru de la edad de la información, de modo que el movimiento web 2.0 está poniendo los cimientos para un crecimiento exponencial del conocimiento y, en consecuencia, 
está teniendo un impacto muy importante sobre la forma cómo la gente vive, trabaja y actúa; más aún, se llega a afirmar que el bibliotecario 2.0 tiene las capacidades, la perspicacia y el conocimiento suficientes como para influir en esta nueva dinámica y para garantizar el futuro de la profesión. Hay que reconocer que en estos debates sobre cuáles han de ser las características de los nuevos profesionales no se entra, en general, en las habilidades respecto a las TIC; lo que se hace es señalar las actitudes o visión general que un bibliotecario debe poseer, planteamiento este que se concreta en principios tales como "mi objetivo es estar allí donde están los usuarios" o "me sitúo en un enfoque experimental para poder cambiar y estar dispuesto a cometer errores". Se elaboran así diversas listas con las habilidades de los nuevos profesionales, listas que inciden más en las habilidades interpersonales y menos en las competencias tecnológicas.

En este sentido Peltier-Davis [Peltier-Davis] presentó una lista de 14 puntos, respecto al bibliotecario 2.0, que incluye elementos tales como: tener la capacidad de aprender rápida y constantemente, tener la propensión a asumir riesgos y a trabajar bajo presión, tener la suficiente habilidad como para hacer posible el cambio y asumirlo, tener sentido del humor y convertirse en un abogado de la profesión. También se han señalado otras cualidades, como el establecer una estrecha conexión con la información y no con la biblioteca en sí misma, aceptar el papel de profesor, actuar con una activa visión de marketing respecto a su trabajo y a la biblioteca e incluso experimentar con el uso de las nuevas tecnologías, aunque manteniendo un sano nivel de escepticismo.

No obstante esta perspectiva focalizada en las cualidades "de comportamiento", podríamos decir, que según algunos deben darse en el bibliotecario profesional, para otros lo esencial son las habilidades en cuanto al conocimiento y las tecnologías de la información (IT), de modo que incluso llegan a señalarse una lista de doce competencias básicas que deben darse en el bibliotecario 2.0.: habilidades para escribir y controlar un blog; crear, descargar y editar fotos, videos, podcasts y escenas de películas; editar un avatar y saber cómo manejar un nuevo aparato. Así mismo, se incluyen habilidades tales como el conocimiento del funcionamiento básico de las tecnologías de información en la biblioteca y de la manera cómo éstas complementan a la biblioteca física, tradicional. También se añade a esta lista la capacidad para poder contar la historia de las bibliotecas mediante los diversos media, tales como la escritura, la fotografía, audio y video y todo lo referente a las creative commons (Como es bien sabido, creative commons es una marca, a la vez que un lema, de una propuesta nueva de copyright derechos de autor - libre en internet. Promueve el compartir conocimientos a partir de obras audiovisuales, musicales, textos, contenidos... libres en internet.

Recientemente el Bulletin des Bibliothèques de France se hacía eco del debate sobre los cauces de información existentes en el mundo profesional de los bibliotecarios franceses; en el resumen de dicho debate se presentaron algunas cuestiones respecto a la profesión de bibliotecario en Francia, hoy día, que 
estimamos de sumo interés y que, pese a las obvias diferencias podrían ser totalmente válidas para los profesionales españoles [Alix-Revelin].

Aparece la función del bibliotecario como algo antiguo, ciertamente, pero el oficio es relativamente reciente, no más allá del siglo XX. Ha sido el desarrollo de las bibliotecas universitarias primero, y de las públicas después, lo que ha permitido, numéricamente hablando, una profesión que se reconoce a sí misma. Se podría afirmar que, aunque esta profesión es heredera de una tradición antigua, la cultura de quienes la ejercen se apoya menos en esta tradición que en ciertos elementos de estructuración reciente:

- El marco en que ésta se desarrolla (esencialmente la función pública)

- La formación, sancionada mediante diplomas fuertemente identitarios (oposiciones de facultativos y ayudantes, diplomaturas y licenciaturas universitarias)

- Las competencias específicas de los bibliotecarios, distintas de las de los documentalistas, archiveros o conservadores de museos

Los elementos estructurales más fuertes en la profesión bibliotecaria, y que permanecen, son el dinamismo y el crecimiento casi continuo del sector de las bibliotecas durante los últimos treinta años; no obstante, los bibliotecarios parecen vivir cada día en un "complejo de identidad" no frenado ni por ese dinamismo antes citado ni por los reconocimientos señalados. La profesión presenta una serie de características tales como:

- Numéricamente, y comparados con otros colectivos, (el de los médicos, por ejemplo) los bibliotecarios son poco visibles.

- Se trata esencialmente de una profesión de funcionarios

- Es realmente una profesión poco mediática, o si se quiere, y en el sermón paladino al uso, "poco glamurosa"

- Replegada sobre sí misma

- Dividida entre los movimientos reivindicativos esporádicos (¡Existimos!) y un complejo de inferioridad interiorizado (casi pidiendo excusas, a veces, por ser bibliotecarios). Según todo lo señalado, si las bibliotecas "reales" aparecen desiertas y las virtuales ahogadas por Google... ¿para qué los bibliotecarios?

En esta fase (¿casi?) final, la profesión se divide entre dos grandes tendencias: la de desarrollo de las bibliotecas y después, en la era digital, la de digitalización. En cuanto al desarrollo, la situación obliga a los técnicos del documento a transformarse en cuadros polivalentes, especialistas en gestión de recursos humanos, gestores, contables, informáticos. La digitalización, por su parte, genera 
una especialización y un tecnicismo crecientes sin cesar. En este panorama, ¿quién se atrevería a señalar que sabe aún lo que realmente es un bibliotecario?

Desde un punto de vista asociativo, se sigue diciendo en el artículo del Bulletin des Bibliothéques de France al que estamos haciendo mención, se percibe una multiplicación de asociaciones de alcance, en el mejor de los casos, puramente regional, como obedeciendo al principio de "si somos dos, creemos una asociación". Esto tiene duras consecuencias para la construcción de las solidaridades profesionales, para la visibilidad exterior del mundo bibliotecario, para su representatividad y para la calidad de los intercambios y los debates. La información sobre las bibliotecas circula hoy día en condiciones que no favorecen ni su publicidad ni su proyección. Para aclarar a qué nos referimos al hablar de información, procede distinguir entre centros de información oficial, revistas en papel, sitios internet, revistas en línea, útiles colaborativos, blogs y listas de difusión [Alix-Revelin].

A partir de este esquema "sociológico", y siguiendo con el enfoque sistémico al que antes nos referíamos, procede señalar cómo la cuestión del personal de las bibliotecas en épocas de crisis (y, lógicamente, los límites de este trabajo no permiten extendernos demasiado) viene en primer lugar condicionada necesariamente (al igual que sucede con toda la biblioteca y con cada uno de sus elementos componentes), por unos profundos recortes presupuestarios. En muchos casos la plantilla se reduce, prescindiendo de los contratados a tiempo parcial; también es normal que no se cubran las bajas que se van produciendo, normalmente por jubilación. Es ciertamente difícil proponer soluciones y lo normal suele ser que se produzcan disminuciones en el horario de atención al público o incluso que lleguen a desaparecer ciertos servicios por falta material del personal que los atiende.

No obstante lo dicho, es factible entender que Sí se puede enfocar la situación desde un nuevo planteamiento de la biblioteca, de lo que representa y de lo que puede aportar a la sociedad. La antes citada Mackenzie afirma que "las bibliotecas están cambiando; de ser predominantemente lugares de transacción se están transformando en centros creativos de la comunidad y en lugares de participación, creación y aprendizaje. Se ha señalado cómo suele darse una visión diferente en los cuadros directivos y el personal de base, de modo que aquellos están en la visión del futuro y en sus sueños de un diferente papel para las bibliotecas mientras que el personal de base se desenvuelve en sus actividades diarias y en sus carencias cotidianas. Como solución algunas bibliotecas (como es el caso la biblioteca pública de Estocolmo) [Estocolmo] han optado por poner en marcha una nueva estructura que redistribuye al personal en tres grupos: enseñanza, lectura y préstamo. Johanna Hansson, la directora, reconoce que debe haber un espacio entre la visión de futuro y el día a día... pero no debe ser demasiado grande, de modo que en Estocolmo el valor de la biblioteca no está en la visión en sí, sino en el encuentro diario entre el personal y el usuario, entre un usuario y otro usuario, entre el usuario y la colección 
de materiales. "Para crear el cambio, dice Hansson, hay que relacionar la visión con el día a día; esto conlleva saber qué se está haciendo, por qué y cómo y poner el foco de atención y la actitud en el usuario y no en la organización de la biblioteca... Debe ser posible que el personal tome sus propias decisiones y que pueda intentar hacer las cosas de manera diferente"[Hansson].

$\mathrm{Ni}$ que decir tiene que en unas estructuras tan burocratizadas y esclerotizadas como las que, en general, se presentan en la inmensa mayoría de las bibliotecas españolas (sean éstas del tipo que sean) un cambio de esta naturaleza es difícil de llevar a la práctica; en cualquier caso, y partiendo de nuestra realidad, sólo queremos señalar que hay otras manera de hacer las cosas.

En este breve análisis sobre el personal bibliotecario en tiempos de crisis estimamos procedente hacer referencia, una vez más, al Manifiesto de la Unesco sobre la biblioteca pública: "El bibliotecario es un intermediario activo entre los usuarios y los recursos. Es indispensable su formación profesional y permanente para que pueda ofrecer servicios adecuados".

Resulta más que evidente que si hay recortes presupuestarios, es probablemente en la franja destinada al personal donde con más fuerza acaba notándose la gravedad de la situación. En este sentido, son destacables los datos que proporciona el informe "Las bibliotecas públicas en España. Una realidad abierta", encargado por la Dirección General del Libro, Archivos y Bibliotecas del Ministerio de Educación y Cultura y publicado en el Boletín Oficial del Estado número 218, con fecha 11 de octubre de 1999, es decir, mucho antes de que estallase la actual crisis económica.

El análisis que respecto a la cuestión del personal en las bibliotecas española recoge es perfectamente asumible a fecha de hoy, 2010, once años después: "La "crisis" se advierte desde el momento en que los municipios, como administración más cercana al ciudadano, han ido incrementando progresivamente los servicios prestados a su población, satisfaciendo con frecuencia aquellas necesidades encomendadas por la ley (recuérdese que los municipios de más de 5.000 habitantes están obligados a facilitar a sus vecinos un servicio de biblioteca pública). A esto se añade la frecuente carencia de recursos en relación con las necesidades a cubrir (recursos materiales, económicos y humanos) y la mermada y poco apurada capacidad normativa de sus consistorios. A título de ejemplo, conviene tener en cuenta que, según las fuentes del Instituto Nacional de Estadística, el 50,3 por ciento de las bibliotecas públicas españolas en 1998, un total de 1.893 centros, estaban ubicados en poblaciones de menos de 5.000 habitantes, es decir, municipios que no tienen obligación legal de crear o mantener un centro de lectura, pero sí consideran la conveniencia de dar este servicio a sus ciudadanos. La mayor parte de esos centros, 1.406 (dos tercios), han sido creados con posterioridad al año 1980. En sentido contrario cabe recordar que hay todavía cierto número de poblaciones de más de 5.000 habitantes, incluso entre ellas alguna capital de provincia, que carece de este servicio cultural básico. [Nogales]. 
Esta situación viene agravada, si ello es posible, por la existencia real y más que comprobada de lo que podríamos llamar como el "bibliotecario orquesta", es decir, el profesional que solo, totalmente solo, ha de "tocar todos los instrumentos". Acudimos de nuevo al citado estudio del Ministerio de Cultura y Educación: "La vinculación del bibliotecario a otras áreas de gestión, cuando se produzca, ha de estar muy justificada. Desde las más tradicionales de Bibliotecario-Archivero o Museólogo, a las más novedosas de Informador Turístico, Agente de Desarrollo Comunitario, Animador Sociocultural, pasando por otras más rocambolescas como Alguacil-Bibliotecario, LimpiadorBibliotecario, y una larguísima serie que podemos encontrar en las convocatorias oficiales de plazas y, sobre todo, en la realidad misma. Sin duda que el bibliotecario puede y en muchos casos debe ser gestor cultural, animador sociocultural, informador turístico, agente de desarrollo comunitario, responsable de publicaciones, etcétera. Pero todas esas cosas las ha de ser en el propio ámbito de la biblioteca, dotando la administración competente de medios y recursos a la biblioteca, sede de esas actividades, y asimilando de manera coherente las plazas del bibliotecario y las de sus colaboradores al mejor nivel y clasificación posible, consolidando plazas que no han de estar al albur de los deseos del responsable político y dimensionando los puestos de trabajo a la realidad de la comunidad a la que ha de atender. En este sentido hay que analizar las figuras del bibliotecario "de plaza única" y el "multifunción" de manera muy distinta, según se trate de municipios de mayor o menor tamaño. No se puede dejar de considerar que en muchas localidades pequeñas la biblioteca pública constituye el único servicio cultural e incluso el único servicio no propiamente administrativo con que cuentan esos ayuntamientos. En esas condiciones parece lógica la tendencia a la integración, frente a la dispersión. Más allá, hay que pretender la máxima integración de las distintas políticas sociales y culturales. Organismos como las diputaciones provinciales o las federaciones de municipios están, parece, especialmente llamados a aportar modelos de gestión que cada municipio adaptará posteriormente a su realidad concreta" [Nogales].

Como venimos diciendo, los recortes presupuestarios están a la orden del día, tanto que ya casi han dejado de ser noticia. Como muestra de lo dicho reproducimos la información aparecida en el diario El País, Andalucía, con fecha de 30/10/2010: "La Junta sólo contratará personal en caso de necesidad y urgencia. El capítulo de personal será uno de los que más se resientan. A la congelación salarial y las restricciones en las "retribuciones de entidades instrumentales" se unen las limitaciones a la contratación de plantilla: solo "se repondrá el 10\% de los efectivos" y la "contratación de personal laboral y el nombramiento del personal funcionario interino se limitará a casos de necesidad y urgencia"...La Consejería de Cultura, entre las que más, pierde un $25 \%$ respecto al 2009".

No parece que sean necesarios más comentarios. Ahora bien, el hecho de que continuamente se estén produciendo recortes en las partidas presupuestarias 
correspondientes al personal no quiere decir que las bibliotecas no puedan actuar de ninguna manera. Quizás el primer elemento en consideración sea huir del voluntarismo. Nos referimos al hecho de que sin medios sólo se puede llegar a casi ningún sitio, por lo que procede tener en cuenta que intentar actuaciones sin un mínimo de instrumentos sólo va a conllevar frustraciones. Tal vez sea más productivo el repensar la biblioteca y lo que realmente ésta significa en la sociedad actual. Así, nos encontramos con centros a los que cada vez se acude menos para consultar libros y materiales en papel y más para entrar en la red, para tener encuentros - reales o virtuales- con otros.

La biblioteca como punto de encuentro, de modo que el acudir a ella aparece como una función superior a cualquier otra. No queremos decir que esto sea realmente nuevo, pero hasta hoy día no se había tenido una noción tan clara del fenómeno. Según esto, y sin dejar de lado la cuestión de la escasez de personal, habría que someter a análisis crítico las tareas tradicionales del personal de la biblioteca: cuáles de éstas son absolutamente intocables, cuáles son modificables e incluso cuáles de ellas son perfectamente suprimibles. Este análisis, repetimos, ha de hacerse con los datos de la realidad: recortes presupuestarios, escasez del personal y, en consecuencia, obligatoriedad de redefinir el papel, o los papeles, básico y esencial. Si a la hora de hacer frente a la crisis no partimos de estos condicionantes, de una realidad ciertamente dura, las cosas podrán ir a peor $\mathrm{y}$, ciertamente, irán.

\section{CONCLUSIÓN}

El análisis de las bibliotecas en estos momentos, y el estudio de hasta qué punto la crisis está afectando a los componentes de éstas, nos muestra la gravedad de la cuestión. De entrada, se puede afirmar que las editoriales y las librerías, como elementos que proveen de materiales a las bibliotecas, están siendo totalmente vulnerables a la crisis. La biblioteca en su conjunto, sus instalaciones y, sobre todo, su personal, también aparecen como especialmente afectadas.

En cuanto al edificio, y contra de lo que se pudiese pensar en una primera aproximación a su análisis desde la perspectiva de la crisis, se siguen construyendo edificios, pero la idea esencial es otra: pensados para y desde el usuario. Edificios en los que, si la biblioteca quiere sobrevivir, no sólo se lee o se toma una obra en préstamo. Eso requiere de los espacios "tradicionales": Soledad, silencio, lugar para el recogimiento y la meditación. Pero también, y al mismo tiempo, espacios para poder tomar un café con los amigos, charlar, asistir a un espectáculo, un evento... Crisis como acicate para ver el edificio desde un nuevo enfoque, más creador, más dinámico, más participativo. La crisis hace que aparezcan nuevos sentidos para la biblioteca física, empezando por su edificio. Hay que saber aprovechar estos nuevos sentidos. 
En la misma medida en que la crisis condiciona al edificio, este va a condicionar, ya lo hemos señalado, la vida profesional y las actuaciones del personal. Ante la crisis, el personal, si sigue trabajando en la biblioteca (hipótesis ésta, la de que muchos profesionales se quedan sin trabajo, nada descartable), ha de tomar una actitud mucho más proactiva: su labor de intermediación no desaparece, en modo alguno; es bien visible, pero el usuario en muchas ocasiones no lo nota. No lo vemos como un nuevo tipo de profesional, sino como el bibliotecario de siempre que sabe usar las nuevas tecnologías para conseguir que la biblioteca sea el lugar (físicamente o en la distancia) donde se aprende, se obtiene información o, simplemente, se está con otra gente. Posiblemente, de la crisis ha de salir, o está saliendo ya, un nuevo profesional cada vez más abierto a sus usuarios, a la sociedad. Crisis como renovación, como nueva fase en la que sólo van a sobrevivir quienes sepan adaptarse.

La crisis está aquí, entre nosotros, y probablemente ha venido para quedarse, y va a durar más tiempo del que sus directos causantes, un capitalismo depredador y una casta política ineficaz hasta el sonrojo, podrían desear. Las bibliotecas, una institución milenaria más que centenaria, la están sufriendo en grado superlativo. No obstante lo dicho, no todo son problemas, también existen soluciones: la amenaza es oportunidad, y adaptarse al sentir de los tiempos supone preparación, voluntad, trabajo, y deseos de permanencia. Aparece como cuestión ineludible tener una nueva idea del edificio como elemento sostenible, de los usuarios como factor primordial en la justificación de la existencia de las bibliotecas y del personal como elemento activo, creador de todo un nuevo entorno.

\section{REFERENCIAS BIBLIOGRÁFICAS}

ALIX, Yves; REVELIN, Gael: "Les bibliothécaaires, combien de divisions?". En Bulletin del Bibliothéques de France, 2009, 54, 4. En: http://bbf.enssib.fr /consulter/bbf-2009-04-0017-002 [Consultado el 20 Enero 2011].

ARENILLA SÉZ, Manuel: "Tu blog de la Administración Pública". En: http://morey-abogados.blogspot.com/2010/03/la-crisis-del-estado-y-de-la.html [Consultado el 14 de Octubre de 2011].

CASTILLO, GÓMEZ Y QUILEZ: CASTILLO FERNÁNDEZ, Javier; José Antonio GÓMEZ HERNÁNDEZ; Pedro QUÍlEZ SIMÓN (Eds.): La biblioteca pública frente a la recesión: Acción social y educativa. Murcia Ediciones Tres Fronteras. Anabad: 2010.

CATALUNYA. GENERALITAT. Subdirecció General de Biblioteques. "Imagina la biblioteca publica del segle XXI. Extracció de dades de les enquestes" En. http://www.imaginalabiblioteca.cat/informe_final.pdf [Consultado el 31/10/11].

DOK. Library Concept Center. http://www.dok.info/index.php?cat=pagina \&pagina_id=110 [Consultado el 13/01/2011]. 
ESTOCOLMO Biblioteca Pública de Estocolmo: http://biblioteket.se/ default.asp?id $=6401 \&$ refid $=5297$ [Consultado el 13/01/2011].

FEDERACIÓN de GREMIOS y EDITORES de ESPAÑA. En: http:// www.elpais.com/articulo/cultura/crisis/golpea/lleno/sector/editorial/elpepucul/2 0090703elpepucul_5/Tes [Consultado el 16 de Octubre de 2011].

FEDERACIÓN de GREMIOS de EDITORES de ESPAÑA. COMERCIO

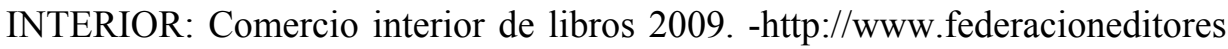
.org/. [Consultado el 15/11/2011].

GRAU, Anna: "Llegan las bibliotecas anticrisis". En $A B C, 03$ de abril de 2009. En: $\quad$ http://www.abc.es/20090403/nacional-sociedad/llegan-bibliotecasanticrisis-200904030236.html [Consultado el 30/10/2010].

HANSSON, Johanna. "All tradition is change: reorganisation and development while planning a new city library in Stockholm". En: http://www.ifla.org/files/ metropolitan-libraries/conferences/Johanna\%20Hansson.pdf. [Consultado el 02/11/2011].

HELSINKI City Library: http://www.lib.hel.fi/en-GB/kirjasto10/kuvia/ [Consultado el 13/01/2011].

HERRALDE, Jorge: En: http://terranoticias.terra.es/cultura/articulo/crisis-noafecta-libros-necesarios-2772611.htm. [Consultado el 29 de Octubre de 2011].

IFLA 2010. SOSTENIBILIDAD. http://www.ifla.org/files/hq/annual-conference/ ifla76/calls-for-papers/ensulib-es.pdf. [Consultado el 15 de Octubre 2011].

JOLIET LIBRARY INFORMATION CRISIS CENTER: Welcome to Joliet Library Information crisis center. En: http://www.jlicc.org/php/index.php . [Consultado el 13/01/2011].

LIBER 2010: Discurso del Presidente de la Federación en la inauguración. - En: http://www.federacioneditores.org/0_Resources/Documentos/Discurso_2010 .pdf [Consultado el 18 de Octubre de 20110].

MACKENZIE, Christine: Emerging themes for public libraries looking forward. En: $\quad$ http://www.ifla.org/files/hq/papers/ifla75/91-mackenzie-en.pdf. [Consultado el 02/11/2011].

MONTAÑES, J. A. "Menos bibliotecas por culpa de la crisis". En EL PAÍS 17 de abril de 20120 www.elpais.com/articulo/cataluna/bibliotecas/culpa/crisis/ elpepiespcat/ [Consultado el 29 de Octubre de 2011].

NOGALES: NOGALES, José María: "El personal de las bibliotecas públicas". En: Las bibliotecas públicas en España. Una realidad abierta. En: http://www.bibliotecaspublicas.info/bp/index2.html. [consultado el 03/11/2011].

OPENBARE BIBLIOTHEEK AMSTERDAM: http://www.oba.nl/ [Consultado el 13/01/2011].

OSLO. Welcome to Deichmanske bibliothek/ Oslo Public Library. http://www.deichmanske-bibliotek.oslo.kommune.no/english/ [Consultado el 13/01/2011]. 
PARADIGMA LIBRO (Blog) En: http://paradigmalibro.com . [Consultado el 18 de Octubre de 2010].

PARADIGMA LIBRO. (Blog) En: http://www.paradigmalibro.com/2010/07/ muerte-subita-de-las-librerias/. [Consultado el 18 de Octubre de 2010].

PAUTAS PULLMAN. "Los nuevos servicios de la biblioteca pública en la sociedad de la información". En: http://dglb.cult.gva.es/images/ pautaspulman.pdf

PELTIER-DAVIS, Cheryl. "Web 2.0, library 2.0, library user 2.0, librarian 2.0: innovative services for sustainable libraries". Computers in Libraries, vol. 29, no. 10, p. 16-21, Nov- Dec, 2009.

UNESCO: Manifiesto de la UNESCO para las bibliotecas públicas. En: http://www.unesco.org/webworld/libraries/manifestos/libraman_es.html [Consultado el 30/10/2010]. 